\title{
DE GODSDIENST DER BOSCHNEGERS DOOR
}

L. JUNKER

\section{III}

Geen godheid der boschnegers, welke bij een der stammen afzonderlijke vereering geniet, verdient de aandacht zoo zeer als de Grautata der Aucaners. Zijn invloed doet zich gevoelen op alle gebieden der samenleving, hij oefent onbeperkte macht uit over lichaam en ziel, hij is de heerscher over de Aucaners in den waren zin van het woord. Door handhaving der oude instellingen waakt hij zorgvuldig, dat de eenheid van den stam bewaard blijft en niet aan diens onafhankelijkheid wordt getornd; als god en orakel zijn in hem al de voorstellingen vereenigd, die voor den primitieve den godsdienst samenstellen; en als vervolger der kwaadwillige toovenarij, de wisi, drukt hij zwaar op de gemeenschap. Zijne samenstelling als godheid is een meesterwerk der priesterkaste, die het verstaan heeft onder voorspiegeling van het denkbeeld „behoud van vrijheid en onafhankelijkheid" door medewerking van den gado aan de leden van den stam een juk op te leggen, dat dezen, niettegenstaande het grooten druk uitoefent, schijnbaar in het geheel niet voelen.

De opperpriester van den fetisch oefent tevens het wereldlijke gezag uit en hierdoor krijgt Grantater ook medezeggenschap in aangelegenheden waarbij de overige samenleving en het bestuur der kolonie betrokken zijn. Het spreekt van zelf dat de fetisch iedere poging tot vooruitgang en verlichting der leden van den stam, zoo hij zelf wil blijven bestaan moet tegengaan en zoodoende tegen alle onderwijs gekant is. De opperpriester echter 
moet, verantwoordelijk zijnde aan het bestuur der kolonie, het doen voorkomen alsof onderwijs gewenscht is en de pogingen van het gouvernement om beschaving aan te brengen ondersteunen. Het laatste geschiedt dan ook voor het oog doch in het geheim worden door Grantata contraorders gegeven.

Volgens de overlevering heeft eene oude vrouw de strijders tegen de blanken met den oorspronkelijken Gwangwella - dit is de werkelijke naam van den fetisch, dien de Djoekas echter, uit vrees niet gaarne uitspreken en hebben zij daarom in zijne plaats het meer aangename Grantata gesteld - bekend gemaakt. Als oorlogsobia moest hij de overwinning brengen en heelde hij de gedurende den strijd verkregen wonden. Na het sluiten van den vrede met de blanken modificeerde de opperpriester hem tot vervolger der wisi: De elkander opvolgende hoofden van den stam volmaakten Grantata meer en meer door de functiën van tal van andere fetischen met die van hem te vereenigen en zoodoende ontwikkelde zich uit de eenvoudige oorlogsobia de volmaakte nationale godheid der Aucaners.

Het voorwerp zelf dat den geest, of zoo men wil de geesten, als woonplaats is aangewezen bestaat uit een wit pakje, ter groote van eene sigarenkistje, dat op eene met pimba wit geverfde plank is bevestigd. De mama (moeder) van den djoekagado bevindt zich te Drietabbetje aan de Tapanahoni. Tegen goede betaling maakt de opperpriester ook Grantatas voor andere dorpen en stammen. Dat een djoekagado, volgens boschnegertoestanden beoordeeld, niet goedkoop is ondervond ik in 1917. Ten westen van de Granrio naar balata pospecteerende had ik een boschneger, Sotia van Goddo, in dienst. Op een goeden dag vroeg hij om vier dagen verlof teneinde in de gelegenheid te zijn Amanakeni, den broeder van het groot opperhoofd, als gids naar de Tapanahoni te dienen. Na zijn terugkeer deelde Sotia mij mede, dat de broeder van $\operatorname{den}$ Granman $f 320^{1}$ ) als schatting voor den djoekagado,

\footnotetext{
1) Sotia zeide fo doezoe fo Saramacca .De Saramaccaners rekenen met twee eenheden, de sreng $=f 0.08$ en de banknotoe $f 0.50$. Om bijv. het be-
} 
den Grantata van het dorp Penpen, had overgebracht. Heeft aanroeping van den Grantata plaats of wil men hem als orakel raadplegen dan wordt de plank uit de hut gehaald, waarin zij blijft opgeborgen; twee boschnegers plaatsen deze met het bundeltje naar boven op hunne hoofden en loopen daarmede rond. Op aan hem gestelde vragen antwoordt Gwangwella door den voorsten drager, die of bevestigend met het hoofd knikt of dit ontkennend schudt.

Te Anjoemakondre aan den Coermotilo woonde ik eens eene processie van Grantata bij. Eene vrouw lag in barensweeën te schreeuwen en te gillen in eene hut. Alle vrouwen van het dorp zaten voor de hut en klapten onophoudelijk met de handen, daarbij ontelbare malen tangie tangie-oöo ${ }^{1}$ ) uitroepend. De mannen stonden voor de deuren van hunne hutten. De twee dragers deden bij elk een aan en ieder mannelijke bewoner van het dorp stelde eene vraag omtrent den afloop der bevalling aan den Grantata. Laatstgenoemde deelde toen aan allen mede dat alles goed zoude afloopen en voordat de plank weder opgeborgen was beviel de vrouw van een tweeling.

Meer malen heb ik kennis gemaakt met de macht van den fetisch en steeds kreeg ik hetzelfde beeld van onvoorwaardelijke onderwerping te zien, met volkomen terzijdestelling van al hetgeen anders den boschneger aan zijn psychisch milieu bindt; bijzonder troffen mij de verontachtzaming der lijkgebruiken en de verbreking van de bloedverwantschap terwille van deze macht.

Op een grondje aan de Boven-Suriname hielden zich tijdelijk eenige Aucaners op, die aan de Sarakreek tehuis behoorden en aldaar het houtkapbedrijf uitoefenden. Ten deele hadden zij hunne vrouwen en kinderen bij zich.

drag groot $f 9.25$ uit te drukken zegt de boschneger een honderd, twee banknotoe en drie sreng. (Wan hondroe, toe banknotoe nanga die sreng), d.w.z. honderd maal acht centen, twee halve guldens en drie maal acht centen. Wan doezoe = duizendemaal acht centen, dus fo (vier) doezoe = $=$ vier maal tachtig gulden.

$\left.{ }^{2}\right)$ tangie tangie, negerengelsch $=$ wees zoo goed; hier, heb medelijden. $\mathrm{Na}$ inwilliging van een verzoek wordt bedankt met Grantangie $=$ hartelijk bedankt. 
Een der mannen kwam te overlijden, doch niemand begon te weeklagen. Gewoon aan het misbaar, dat anders bij zulke gelegenheden wordt gemaakt, verwonderde mij de doodsche stilte en onverschilligheid ten zeerste. Twee mannen vertrokken naar den politiepost Carolina om aldaar een lijkkist te halen. Nadat ze terug gekeerd waren, nam men het lijk uit de hangmat en smeet het ongewasschen in de kist, welke daarna met den meesten spoed werd dichtgespijkerd. Vervolgens namen alle mannelijke personen, die aanwezig waren, de kist op en verdwenen daarmede in een boschpad. Ik stelde bij de achtergebleven vrouwen onderzoek omtrent het vreemde gedoe in en kreeg lakoniek ten antwoord: „Grantata baai hem". (Hij was door Grantata vervloekt).

In 1913 vernam ik aan de Patamacca, dat men aldaar drie dagen voor mijn aankomst het lijk van een oude vrouw ergens in het bosch had gesmeten omdat deze vrouw in leven wisi bezeten had en daarom door Grantata gevloekt was,

In het begin van het jaar was mij door den Gouverneur opgedragen een onderzoek naar de slechte economische toestanden bij de boschnegers aan de Boven Suriname wonende, in te stellen.

Onder meer bleek mij toen het volgende: Te Koffiekamp was kort voor mijn aankomst aldaar een heidensche vrouw overleden die tijdelijk bij hare familie (allen Christenen) had vertoefd. Op haar rustte de vloek van Grantata.

Gedurende mijn aanwezigheid was genoemde familie druk bezig het geld bij elkaar te verzamelen, dat als aflaat naar de Tapanahoni moest worden overgemaakt. Deze Christenen, die de gebruiken van Grantata zoo stipt opvolgden, hadden letterlijk niets te eten; aan het gouvernement zijn zij een vrij groot bedrag verschuldigd voor verstrekte rijst, dat zij niet kunnen afdoen en last but not least wegens gebrek aan geld kunnen zij den bouw van een kerkje niet voltooien.

Uit vorenstaande staaltjes blijkt, dat destraf van Grantata vreeselijk is en het lijkt bijna ongeloofelijk, dat niemand tegen de toepassing ervan in verzet komt, ja dat 
zelf Christenen door hunne familiebetrekkingen aan de macht van den fetisch onderworpen blijven. Ieder is even bang door verzet aan de wraak van Grantata ten offer te vallen, ieder vreest bij het eerste sterfgeval of door den Kromantigado, of door een andere winti door het drijven van fanatieke aanhangers, beschuldigd te worden over wisi te beschikken.

De last van den fetisch is inderdaad bijna ondragelijk voor sommige families. Gedurende bovengenoemd onderzoek bleek mij voorts, dat op de dorpen der Aucaners aan de Sarakreek negentien personen zware geldelijke verplichtingen aan den fetisch hebben.

De inkomsten van den opperpriester beperken zich geenszins tot de bovengenoemde: de aanmaak der amuletten, van de zoogenaamde libitétei (levenslinten) brengt eveneens groote sommen in de schatkist van Grantata ${ }^{1}$ ).

Terwijl verzet tegen de macht van Gwangwella onmogelijk is, verzetten zich de uitvoerders van zijnen wil in 't geheim tegen alle maatregelen door het bestuur der kolonie in te voeren. Zoo werd met den posthouder overeengekomen, dat voortaan de lijken binnen drie dagen na overlijden zouden begraven worden. Aan den Kapitein Amade op Bakoekondre aan de Sarakreek werd echter de geheime opdracht gezonden, dat niets aan de oude instellingen veranderd mocht worden en dat het bij de belofte aan het gouvernement, betreffende de begrafenissen gegeven, maar moest blijven. Hoe stipt de wensch van Grantata werd opgevolgd bleek in Juni 1923. Amade kwam te overlijden en van af zijn dood tot zijn teraardebestelling verstreken tien dagen.

Geen der onderstammen der Saramaccaners bezit een godheid, welke in zoo hooge mate invloed op de geheele samenleving uitoefent als de Grantata dit bij de Aucaners doet. Op drie dorpen Dangogo, Penpen en Kadjoe heeft men den djoekagado van de Aucaners overgenomen.

1) Een amulet van den Grantata kost ongeveer vijftig gulden. In den regel moet voor een libitétei worden gegeven: 50 pantjes, dat zijn ongeveer een meter lange stukken goed dat de vrouwen als korte rokken dragen, twee flesschen sterke rum en eenige flesschen bier. 
Uit den tijd van den strijd met de blanken bestaan nog twee oorlogsobias, de Granobia te Dahome Nawie en de Loangogado Ania genoemd.

Over eerstgenoemde heb ik reeds eenige mededeelingen in het eerste opstel over de Saramaccaners gedaan en kan ik hier met eenige aanvullingen en wijzigingen, die bij nader onderzoek te mijner kennis zijn gekomen, volstaan.

De Nawie is de eenige fetisch aan wien nog bloedige offers worden gebracht. Ook is deze obia daarom nog merkwaardig, dat een mensch in haren dienst tot fetisch wordt. Men heeft in dit geval niet te doen met het boven beschreven tijdelijk bezeten zijn door eenen geest. Door eene wijding, door tooverwerk wordt de geest van den Nawie blijvend in de persoon van den priester gebracht, die gedurende zijn leven den fetisch blijft bedienen. Door de bezwering of wijding, dus toovenarij, bij de handeling verricht, wordt $\mathrm{m}$. i. de eigenschap als mensch-fetisch bepaald.

De hut van Nawie bestaat uit twee, door een tusschenwand gescheiden kamers. Zal aan den fetisch geofferd worden dan verzamelen zich de mannen in de groote voorkamer. De priester zit op een hoogen stoel welke op een podium staat, terwijl de overigen op lage bankjes plaats nemen. Door een der mannen wordt een haan geslacht en het bloed in een kalebas opgevangen. Vervolgens wordt eerst de priester met het bloed besprenkeld en hem daarna de kalebas met de rest van het bloed aangereikt. Hiermede begeeft hij zich naar de achterkamer, de woning van den Nawie zelf en brengt aldaar het offer. Geen ander sterveling mag ooit de achterkamer betreden. Geloofd wordt dat Nawie ieder indringer ter plaatse doodt.

Omtrent de gedaante van het voorwerp, dat den geest als huisvesting dient, kon ik niets te weten komen. Men offert den fetisch op geregelde tijden en noemt de handeling dan wasi na gado (den god reinigen, te eten geven) en wanneer zijn hulp als heelmeester bij verwondingen en beenbreuken wordt ingeroepen.

De Loangogado, de andere oorlogsobia der Sara- 
maccaners, bestaat uit twee onderdeelen, de Ania en de Waënsa of Kadeesa. Eerstgenoemde wordt nog altijd als oorlogsobia, even als de Granobia, in gereedheid gehouden. In October 1922 werd hij tegen mij van uit het dorp Booikoetoe naar de Suriname-rivier gebracht om de booten, waarmede ik met soldaten aan de Bovenrivier zoude komen, tot zinken te brengen. Een collector van balata, die op het dorp overnachtte en die door het vreeselijke geraas, dat bij de processie gemaakt werd te middernacht in zijn slaap werd gestoord, vertelde mij het gebeurde.

De hoofdfetisch moet een uit hout gesneden figuur zijn, die een tijger voorstelt. Hij wordt op het dorp Dam bij de Nassynegers bewaard.

De Waënsa of Kadeesa is de geneeskundige afdeeling van den Loangogado. De fetisch bestaat uit een groote hoop aarde in den vorm van een afgeknotten kegel die rondom met palmbladeren bedekt is. De fetisch, die bij het dorp Dam staat, heeft aan de basis een middellijn van ruim drie meters. In den kegel is een groote pot ingegraven, die den geest tot woning dient. De obia is bijzonder goed voor zieke, zwangere vrouwen en wordt overigens door de Nassynegers den Kromantigado terzijde gesteld.

De Awana-, Nassy- en Loangonegers zijn de bezitters van dezen fetisch.

De Loangonegers bezitten buitendien nog een obia, die den Grantata der Aucaners aan gestrengheid verre overtreft, omdat hij bezitter van wisi, die in zijne nabijheid komen en zelfs leugenaars en dieven, terstond doodt.

Zijn hoofdverblijfplaats is te Stonoehoekoe aan de Granrio., waar zijn offerhut staat. Hij woont echter niet in de hut, doch in een grooten boom, die achter de hut staat en die Pajoenkoe bakahoso ${ }^{1}$ ) genoemd wordt.

De fetisch wordt kort Pajoenkoe genoemd. Hij is een uitmuntende heelmeester en brengt verdwaalden in het

1) baka hoso $=$ achter het huis, de hut. Pajoenkoe bakahoso vertaald is dus Pajoenkoe (naam van den fetisch) die achter het huis staat. Men vertelde mij, dat de boom, die aan den geest tot woning is gegeven nergens anders in de bosschen van de Boven-Suriname voorkomt. 
bosch hulp door hun te zeggen terplaatse te blijven wachten totdat de door de obia uitgezonden personen hen gevonden hebben.

Mijn vriend Asodro, een adept van Pajoenkoe, heeft, zooals hij mij vertelde, te Birihoedoematoe aan den geest een plaats in het om het dorp liggende bosch aangewezen, omdat de boom waaraan de voorkeur gegeven wordt, aldaar niet groeit.

De ingewijden in de geheimen van den fetisch worden na opwekking door den geest ervan bezeten. $Z$ ij oefenen de geneeskunde uit en zijn bijzonder als heelmeester gezocht. De voor de bereiding der medecijnen benoodigde kruiden, bast en bladeren van boomen verzamelen de ingewijden gedurende den tijd dat zij door den geest bezeten zijn; dezen worden dus door den laatste aangewezen.

Ophet dorp Malobbi staat de hut van een watergod, die aldaar gedurende de te zijner eere gehouden wordende plechtigheden vertoeft. Eeneige potten van zwarte klei gebakken dienen hem dan als huisvesting. In de potten, welke op bankjes staan, bevindt zich een mengsel van pimba, gestampte planten en water. $\mathrm{Na}$ afloop van de plechtigheden keert Tonnee, zoo heet de watergeest, weder naar zijn vaste woning in de rivier terug en alle bewoners van het dorp doen hem uitgeleide. Mannen, vrouwen en kinderen gaan de rivier in en nemen aldaar gemeenschappelijk een bad. Na het bad besmeren zij hun geheele lichaam met pimba. Niemand mag gedurende het baden een ander persoon met water bespatten. ${ }^{\mathbf{1}}$ )

In Maart 1923 verraste ik de bewoners van het dorp Doeatta in het bad, en toen kort daarna eene zware regenbui viel (ik moest een onderkomen in het dorp zoeken) kreeg deze stoornis de schuld. Tonnee was er kwaadover geworden.

Als regengod heeft Tonnee groote beteekenis voor den geheelen stam der Saramaccaners. Zoowel bij lang aanhoudende regens als ook in het tegenovergestelde geval,

1) Overtreding van deze Kina van den god straft deze met zware, lang aanhoudende regens welke de veldgewassen bederven. De bespatte persoon wordt bovendien nog ziek. 
gedurende een abnormalen drogen tijd, wordt Tonnee aangeroepen en worden hem offers gebracht teneinde hem te verzoeken kentering in de heerschende weersgesteldheid te brengen.

Personen, die in de rivier verdrinken, worden als door Tonnee gedood beschouwd. Omtrent een Tonnee-mie ${ }^{\mathbf{1}}$ ) doet door den geheelen stam een wonderbaarlijk verhaal de ronde.

Een ongeveer tienjarig meisje geraakte op den Mamadam (een groote waterval) te water. $\mathrm{Na}$ verloop van zeventien dagen werd het kind door huiswaarts keerende boschnegers op dezelfde plaats levend teruggevonden. Het kind vertelde, dat nadat het in het water was terecht gekomen, iemand het had opgenomen en het naar een prachtig huis gebracht had. Aldaar werd het zeer goed behandeld en door kleine meisjes bediend. Het meisje kreeg echter slechts wortelen en zonder zout gekookt voedsel te eten. Haar verlangen naar wat met zout gekookte rijst werd zoo groot dat zij begon te huilen. Men kreeg toen in het huis van Tonnee medelijden met het kind en bracht het weder naar de bovenwereld terug, naar de rots van waar zij in het water was gevallen.

$\mathrm{Al}$ de genoemde fetischen zijn van Afrikaanschen oorsprong. Te Pikien Slee wordt door de Domininegers een godheid vereerd, die zooals de negers zich uitdrukken, hunne voorouders in het bosch gevonden hebben.

Ma Foenkoe is een uit hout gesneden beeld. Zijn geest beschermt de Domininegers; hij geeft hun rijke oogsten, geneest de krankzinnigen van den geheelen stam en heeft buitendien eene zeer goede obia, die verdwaalden in het oerwoud het goede pad aanwijst en met den geest van ieder gewenscht persoon in kontakt kan komen.

Aan den fetisch is de roode aarde gewijd. Voor de offerplechtigheden gebruiken zij de roode klei van de laterietheuvels nabij de Jodensavanne. Niet ver verwijderd van

1) $\mathrm{Mie}=$ Kind.

Het meisje hoorde te Malobbi tehuis. 
deze heuvels hebben hunne voorouders op Palmeneribo als slaven gewoond.

De bovengenoemde obia wordt Siba genoemd. Zij bestaat uit een aantal dunne houten stokjes die tot eene lange buis zijn gebonden. In deze buis wordt zoowel gesproken als ook op antwoord geluisterd. Een verhaal, dat ik omtrent de werking van de obia vernam zal ik hier mededeelen.

Een Dominineger had zich met zijn zoon op de vrachtvaart naar Cayenne begeven. Deze man, Wawa genaamd, keerde na eenigen tijd alleen naar zijn dorp terug, de jongen was met andere negers gaan arbeiden en met dezen achter gebleven. De familie van dezen jongen maakte groot misbaar en eischte dat Wawa terug zoude keeren om zijn zoon, op wien hij volgens boschneger opvattingen geene rechten bezat, te halen en aan de familie terug te geven. Op een kroetoe (vergadering) werd besloten, dat men eerst met behulp van de obia inlichtingen omtrent den te Cayenne achtergebleven boschneger zoude inwinnen en daarna naar omstandigheden handelen.

De priester begaf zich in de hut van Mafoenkoe, riep dezen aan en verzocht onder aanbieding van een rijkelijk offer aan rum, dat de teruggekeerde boschneger moest verstrekken, hem, den priester, door de Siba met den geest van den jongen man in Cayenne te verbinden. Daarbij werd gezegd: deze mocht dood of levend zijn. De bede van den priester werd door Mafoenkoe verhoord, door de Siba vernam de priester, dat de jonge springlevend te Poaki, een plaatsje in Cayenne, vertoefde en goed werk had. De bere (familie van moederszijde) was hierdoor, bijzonder echter door het vooruitzicht dat de jongen met veel goedoe (rijkdom) terug zoude keeren, tevreden gesteld en Wawa behoefde niet meer te vertrekken.

De Alaisanegers bezitten tenslotte nog een orakel en de Papotonegers vereeren op bepaalde tijden een godheid Gran Peté genaamd.

Het eerste, dat op het dorp Marechalskriki zich bevindt, is, zooals mij meerdere negers verzekerden, geen obia doch een sooi (godsoordeel) waaraan zich van diefstal 
verdachte personen onderwerpen. De sooi wijst den werkelijken dief aan en geeft op waar zich het gestolen goed bevindt.

Omtrent de godheid der Papoto kon ik geene inlichtingen verkrijgen. Het schijnt een soort mannenbond te zijn, die op bepaalde tijden onder inachtneming van de allergrootste geheimzinnigheid bij een groote kankantrie in de nabijheid van een plaats, Djemi genoemd, vergadert en aldaar offert.

Herhaaldelijk is boven de naam Kromantigado genoemd. Onder dezen naam stellen zich alle negers een geest voor, die de oorzaken der ziekten opspoort en aanwijst en tevens de middelen aan de hand doet dezen te genezen. Hij oefent zijne kunst door menschen uit in welke hij vaardig wordt. Dezen zijn verplicht aan den geest rijkelijk, bij voorkeur met rum, te offeren. Teneinde het offer in de grootstmogelijke nabijheid van den geest te brengen drinkt de discipel de offergave zelf op, meestal met het gevolg dat de geestverrukking hierdoor tevens verdubbeld wordt.

Bij een zieke geroepen betast de kromanti dezen en doet daarna eerst uitspraak over de oorzaak. Is het gevaarlijk eene persoon van wisi te beschuldigen dan noemt hij een winti, die de zieke beleedigd heeft en die zich thans op hem wreekt.

Terwijl nu voorbereidingen worden getroffen om zich met de oorzaak te verzoenen, offert de kromanti eenige malen om daarna als praktisch therapeut de middelen voor te schrijven die in en uitwendig door den patient moeten gebruikt worden.

Intusschen is een orkest van groote en kleine trommen bij elkaar gebracht en wordt gran prisie (veel plezier) gemaakt. Bij de tromslagers, die een helsch lawaai maken, staat een man met eene kalebas, die van een deksel voorzien is. Men noemt deze een Apakie. Hij heeft de kalebas in de eene en het deksel in de andere hand. Plotseling sluit hij de kalebas met het deksel en op hetzelfde oogenblik houdt ook het lawaai met de trommen op. Met een tevreden lach op zijn tronie verlaat de kromanti de hut 
om in zijn hangmat den dubbelen geest kwijt te raken.

Wat is er gebeurd?

De winti, die door den zieken boschneger beleedigd was geworden en die rondom de plaats zweeft, wachtende om het weegeklaag der vrouwen en kinderen te vernemen, hoort plotseling in de hut vreugde-muziek. Nieuwsgierig sluipt hij de hut binnen op het orkest af. Daar wordt hij door den man met de kalebas, die hem heeft zien binnen komen, geknipt.

De gevangen winti wordt op grooten afstand van den zieke in het bosch gebracht, hem wordt aldaar geofferd en men verzoekt hem van den zieke af te zien. Men belooft hem de vrijheid weer te geven zoodra hij belooft den zieke niet weer te kwellen. Het laatste geschiedt altijd, hoe weet ik niet.

Sterft de zieke dan treft niet den kromantigado doch diens dicipel de schuld. Laatstgenoemde heeft dan iets tegen den geest misdaan en deze heeft den dokter op een dwaalspoor gebracht. (Na gado pori na winti).

Zoo werkt de god der geneeskunde bij de boschnegers. Doch niet bij de boschnegers alleen. De Kromanti is in geheel Suriname verspreid. Onder de creolen bevolking van de Boven-Suriname zijn mij vier personen bekend met Kromanti-winti.

Ook de andere winti der boschnegers hebben onder de creolen vele vertegenwoordigers. De papawinti wordt bijv. door vrouwen uit Paramaribo op de goudplacers aan de Sarakreek aan den arbeid gesteld om den concessiehouders de plekken aan te wijzen waar hij het goud verborgen houdt.

In al het vorenstaande is in grove trekken medegedeeld hetgeen ik omtrent de Godsdienstuitingen der boschnegers heb te weten kunnen komen.

De van den godsdienst afhankelijke zeden en gebruiken hoop ik eveneens nog in een opstel te behandelen teneinde het beeld van het psychich leven der boschnegers den lezers zoo volledig mogelijk voor oogen te stellen.

Boven Suriname, December 1923. 